\title{
VIGÊNCIA E PRORROGAÇÃO DOS CONTRATOS POR ESCOPO CELEBRADOS COM ENTES PÚBLICOS
}

\section{DURATION AND EXTENSION OF SCOPE CONTRACTS WITH PUBLIC ENTITIES}

\author{
Kristian Rodrigo Pscheidt ${ }^{1}$
}

\section{RESUMO}

A Administração Pública pauta-se pelos corolários da legalidade e efetividade. Assim o é com relação aos contratos administrativos e procedimentos licitatórios, consoante as disposições da Lei 8.666/1993. Ocorre que existe omissão legislativa acerca dos contratos por escopo, em específico com relação ao prazo de vigência e prorrogação. Nesse vácuo, a jurisprudência pátria tem seguido a orientação da Advocacia Geral da União, que exige novo procedimento licitatório sempre que vencido o prazo contratual. Ocorre que essa orientação não pode ser seguida de forma irrestrita, sob pena de violação da efetividade indicada no artigo 37 da Constituição. Isso ocorre, por exemplo, na contratação de escritórios de advocacia e assessoria contábil por escopo, com honorários atrelados ao êxito.

Palavras-chave: Licitação; Contratos por escopo; Renovação; Efetividade.

\begin{abstract}
Brazilian Government is guided by the principles of legality and effectiveness. For example, there are the administrative contracts and tender procedures, according to the provisions of Law n. 8.666/1993. It happens that there is legislative omission about the scope contracts, in particular regarding the validity period and renovation. In this vacuum, Tribunals has followed the guidance of the Union General Attorney, which requires new bidding process whenever expires the contract. But that guidance can not be followed without restriction, under penalty of violation of effectiveness indicated in Article 37 of the Constitution. This occurs, for example, in hiring law firms and accounting advice in scope, with fees tied to the success.
\end{abstract}

Keywords: Bidding; Scope Contracts; Renovation; Effectiveness.

\footnotetext{
${ }^{1}$ Professor dos cursos de graduação e pós-graduação em Direito pela Universidade Tuiuti - Paraná, (Brasil). E da Faculdade CNEC. Paraná (Brasil). E-mail:kristian_adv@ hotmail.com
} 


\section{INTRODUÇÃO}

A Administração Pública, na defesa dos interesses coletivos, está pautada pelo princípio da legalidade. Seus atos e manifestações devem estrita obediência à forma e rigores do ordenamento jurídico. É fato ínsito ao seu próprio conceito que se constitui na "tradução jurídica de um propósito político, o de submeter os exercentes do poder em concreto - administrativo - a um quadro normativo que embargue favoritismos, perseguições ou desmandos" (MELLO, 2006, p. 57).Assim o é, por exemplo, frente à Lei n. 8.666/1993, no tocante aos requisitos essenciais dos contratos administrativos.

Ocorre que a infinidade de situações concretas desvenda um conjunto de fatos que, em um primeiro momento, não encontra correspondência direta no ordenamento jurídico. Surgem então os instrumentos de integração do direito, expressos no artigo $4^{\circ}$ da Lei de Introdução às Normas do Direito Brasileiro (Decreto-Lei n. 4.657/1942), que determinam que, quando a lei for omissa, o juiz decidirá o caso de acordo com a analogia, os costumes e os princípios gerais de direito.

De tal maneira, o Direito mostra-se "completável", na medida em que o próprio sistema jurídico estipula meios para sua completude ${ }^{2}$. Ocorre que analogia, costumes e princípios gerais do direito caracterizam um campo de atuação de que exigem escolhas, ou seja, admitem uma discricionariedade.Não representam a expressa vontade da lei, mas sim daquele que a aplica ${ }^{3}$.Surge assim a questão problemática de como a Administração Pública deve atuar quando encontrar-se frente a uma lacuna do direito.

Como exemplo prático, real e que vem criando nítida insegurança jurídica àqueles envolvidos, tem-se a questão darenovaçãodos contratos de escopo com osentes públicos. Está previsto na Lei que os contratos de prestação de serviços contínuos são

\footnotetext{
2 "Ocorre que a alta complexidade das sociedades contemporâneas torna impossível ao Estado regular todas as relações jurídicas visto que a prática social faz surgir novas espécies de relações a todo o momento. Tem-se, então, que o ideal de um ordenamento jurídico completo se mostra inalcançável, todavia, tal ordenamento deve ser no mínimo completável para que possa cumprir seu desiderato de ordenação social" (MARTINS, 2013, p. 53).

3 "Esgotados todos os recursos da Lei, os da analogia, os das formas suplementares, os da analogia, aplicada às formas suplementares, o último meio de integração da norma jurídica, já que o magistrado não pode eximir-se de julgar, é a equidade, o princípio do direito natural, semelhante e complementar à justiça" (FRANÇA, 1988, p. 61)
} 
limitados ao prazo máximo de sessenta meses, sendo expressamente vedado o contrato com prazo de vigência indeterminado. O rigor da justifica-se por si, como regra geral, com base nas noções de supremacia de interesse público, da indisponibilidade, razoabilidade e proporcionalidade. É a redação do art. 57 da Lei de Licitações, que apresenta a seguinte redação:

\footnotetext{
Art. 57. A duração dos contratos regidos por esta Lei ficará adstrita à vigência dos respectivos créditos orçamentários, exceto quanto aos relativos:

II - à prestação de serviços a serem executados de forma contínua, que poderão ter a sua duração prorrogada por iguais e sucessivos períodos com vistas à obtenção de preços e condições mais vantajosas para a administração, limitada a sessenta meses;

$\S 3^{\circ}$ É vedado o contrato com prazo de vigência indeterminado.

$\S 4^{\circ}$ Em caráter excepcional, devidamente justificado e mediante autorização da autoridade superior, o prazo de que trata o inciso II do caput deste artigo poderá ser prorrogado por até doze meses.
}

A dúvida surge como proceder com a renovação do contrato quando, por exemplo, um escritório de advocacia é contratado regularmente para conduzir uma demanda judicial ou uma assessoria contábil visando a recuperação de créditos cuja homologação depende da autoridade fazendária, cujos honorários estão atrelados ao êxito da medida. Sabe-se que demandas judiciaisou administrativas de grande complexidade, de forma corriqueira, extrapolam o prazo máximo de 60 meses de tramitação. De tal forma surge a dúvida de comoeste contrato pode ser estendido na sua duração, haja vista não se ter atingido o seu escopo, qual seja, o término de demanda contenciosa proposta.

Como compatibilizar a situação com os ditames gerais dos contratos administrativos, com destaque para as disposições do artigo 57, II combinado com o $3^{\circ}$ da Lei n. 8.666/1993? Trata-se de uma prestação de serviços contínua? Aplica-se o limite de 60 meses?

Neste sentido é que se busca caminhar pela doutrina e jurisprudência, com destaque para as posições dos Tribunais de Contas, almejando-se traçar os contornos legais para a solução deste problema.Seria razoável e proporcional exigir nova contratação sempre que exaurido o prazo de 60 meses, mas ainda não encerrada a demanda contenciosa? 


\section{I.AS DISPOSIÇÕES DA LEI 8.666/1993SOBRE OCONTRATO DE PRESTAÇÃO CONTÍNUA}

O primeiro aspecto a ser desenvolvidodiz respeito ao paralelo existente entre a prestação de serviços de forma contínua em face da prestação de serviços por escopo. São situações distintas, sendo que apenas o segundo caso (escopo) será objeto de desenvolvimento aprofundado neste estudo. Não se pode confundir a "contrato de execução instantânea (ou de escopo)"com o "contrato de execução continuada", conforme distinçãode Marçal Justen Filho (2012, p. 828-829):

\begin{tabular}{|c|c|}
\hline EXECUÇÃO INSTANTÂNEA & EXECUÇÃO CONTINUADA \\
\hline $\begin{array}{l}\text { Os contratos de execução instantânea impõem à } \\
\text { parte o dever de realizar uma conduta } \\
\text { específica e definida. Uma vez cumprida a } \\
\text { prestação, o contrato se exaure e nada mais pode } \\
\text { ser exigido do contratante (excluídas as hipóteses } \\
\text { de vícios redibitórios, evicção etc.). Assim se } \\
\text { passa, por exemplo, com o contrato de compra e } \\
\text { venda à vista de um imóvel. Tão logo o vendedor } \\
\text { promova a tradição da coisa e o comprador liquide } \\
\text { o preço, o contrato está exaurido. É usual aludir-se } \\
\text { a contrato de escopo para indicar essa espécie, mas } \\
\text { essa expressão também propicia dúvidas, eis que } \\
\text { todo e qualquer contrato tem um "escopo", na } \\
\text { acepção de uma finalidade ou objetivo. }\end{array}$ & $\begin{array}{l}\text { Já os contratos de execução continuada impõem à } \\
\text { parte o dever de realizar uma conduta que se } \\
\text { renova ou se mantém no decurso do tempo. Não } \\
\text { há uma conduta específica e definida cuja } \\
\text { execução libere o devedor. Assim se passa, por } \\
\text { exemplo, com o contrato de locação. O locador } \\
\text { deve entregar o bem locado ao locatário e } \\
\text { assegurar-lhe a integridade da posse durante o } \\
\text { prazo previsto. Outro exemplo é o contrato de } \\
\text { prestação de serviços de limpeza, que impõe ao } \\
\text { contratado a obrigação de realizar a mesma } \\
\text { atividade todos os dias. Nesse caso, a execução } \\
\text { pelo contratado da atividade de limpeza no edifício } \\
\text { no primeiro dia do contrato não significa o } \\
\text { exaurimento do objeto contratual. }\end{array}$ \\
\hline
\end{tabular}

Sendo assim, os contratos por escopo impõe um resultado certo e final, enquanto que nos contrato de execução contínua importa na verificação de uma mesma atividade todos os dias. Para melhor elucidar, invocam-se também os termos da Instrução Normativa da Secretaria de Logística e Tecnologia da Informação (SLTI) nº. 02/2008 e subsequentes alterações, da qual decorre que:

SERVIÇOS CONTINUADOS são aqueles cuja interrupção possa comprometer a continuidade das atividades da Administração e cuja necessidade de contratação deva estender-se por mais de um exercício financeiro e continuamente.

O contrato de execução continuada visa atender a necessidades permanentes da Administração, a exemplo das obrigações de fazer envolvendo os serviços de limpeza e de conservação, de Segurança e Vigilância, de Recepção, Telefonista, Informática, de 
copeiragem e garçom, de Transporte, de Reprografia, de Telecomunicações, de manutenção de prédios, equipamentos e instalações.A propósito, é a definição abarcadapelo Tribunal de Contas da União ${ }^{4}$, consoante exemplo abaixo ementado:

\begin{abstract}
Serviços de natureza contínua são serviços auxiliares e necessários a Administração no desempenho das respectivas atribuições. São aqueles que, se interrompidos, podem comprometer a continuidade de atividades essenciais e cuja contratação deva estender-se por mais de um exercício financeiro. O que é continuo para determinado órgão ou entidade pode não ser para outros. São exemplos de serviços de natureza contínua: vigilância, limpeza e conservação, manutenção elétrica, manutenção de elevadores, manutenção de veículos etc. Em processo próprio, deve a Administração definir e justificar quais outros serviços contínuos necessita para desenvolver as atividades que lhe são peculiares. (TCU. Licitações e contratos: orientações e jurisprudência do TCU/Tribunal de Contas da União. 4. ed. rev., atual. eampl. Brasília: TCU, Secretaria-Geral da Presidência; Senado Federal, Secretaria Especial de Editoração e Publicações, 2010, p. 772) [sem grifos no original]
\end{abstract}

Os serviços que dão ensejo a um contrato de execução continuada são instrumentais, auxiliares ou acessórios, ou seja, constituem atividade de apoio, a fim de que a administração possa cumprir sua missão institucional. Como estão envolvidas atividades de apoio, que são permanentemente necessárias, o produto esperado não se exaure em período predeterminado. Pressupõe-se vigência da contratação por mais de um exercício financeiro, daí a legislação ter possibilitado, pelo art. 57, II, da Lei de Licitações, a renovação do contrato afim.

Para a prorrogação desses contratos, que não se confundem com os contratos por escopo, faz-se necessário, antes de tudo, a presença dos requisitos legais previstos no art. 57, inciso II e $\S 2^{\circ}$, quais sejam: limite de vigência total de 60 meses; preços e condições mais vantajosas para o ente público; justificação por escrito; e prévia autorização da autoridade competente.

A Instrução Normativa $\mathrm{n}^{\circ}$. 02, de 30 de abril de 2008, do Ministério do Planejamento, Orçamento e Gestão, disciplina a contratação de serviços por órgãos ou entidades integrantes do Sistema de Serviços Gerais -SISG. O caput do seu art. 30

\footnotetext{
${ }^{4}$ Veja-se que conforme a Decisão no ${ }^{\circ} \cdot 1.136 / 2002$, do Plenário do Tribunal de Contas da União, para se enquadrar os serviços como continuados, "é necessário analisar os contratos caso a caso e confrontá-lo com a forma de atuação da DFA/PR, cabendo para o caso determinação para que o órgão, ao firmar e prorrogar contratos, observe atentamente o inciso II do art. 57 da Lei 8.666/93, de forma a somente enquadrar como serviços contínuos contratos cujos objetos correspondam a obrigações de fazer e a necessidades permanentes".
} 
repete a restrição de vigência do contrato à vigência do crédito orçamentário, remetendo o trato das exceções ao art. 57 da Lei n. 8.666/93.Por sua vez, o art. 30-A, com a redação conferida pela Instrução Normativa n. 06, de 23 de dezembro de 2013, traz as condições de prorrogação específicas para os contratos de serviços contínuos ${ }^{5}$.

Diz a legislação que o valor do contrato deve permanecer vantajoso para a Administração e que essa vantajosidade muitas vezes poderá ser aquilatada por pesquisas de mercado. $\mathrm{O}$ art. 30-A da Instrução Normativan. 02/2008 do Ministério do Planejamento, Orçamento e Gestão também estabelece os requisitos para a renovação contratual, podendo-se enumerar os seguintes itens:
1) interesse da Administração na continuidade dos serviços;
2) interesse expresso da contratada na prorrogação;
3) limite total de vigência de 60 meses;
4) prestação regular dos serviços até o momento;
5) obtenção de preços e condições mais vantajosas para a Administração;
6) redução ou eliminação dos custos já pagos no primeiro ano;
7) respeito aos limites de preços estabelecidos pelo Ministério do Planejamento, Orçamento e Gestão;
8) aprovação formal pela autoridade competente.

Por fim, vale mencionar também a Orientação Normativa da Advocacia Geral da União (AGU) nº. 38/2011:

\begin{abstract}
Nos contratos de prestação de serviços de natureza continuada deve-se observar que: a) o prazo de vigência originário, de regra, é de até 12 meses; b) excepcionalmente, este prazo poderá ser fixado por período superior a 12 meses nos casos em que, diante da peculiaridade e/ou complexidade do objeto, fique tecnicamente demonstrado o benefício advindo para a administração; e c) é juridicamente possível a prorrogação do contrato por prazo diverso do contratado originariamente.
\end{abstract}

Surge a denominada prorrogação excepcional, prevista no $\S 4^{\circ}$ do art. 57 da Lei n. 8.666/93, que autoriza "em caráter excepcional, devidamente justificado e mediante

\footnotetext{
${ }^{5}$ Art. 30-A Nas contratações de serviço continuado, o contratado não tem direito subjetivo à prorrogação contratual, que objetiva a obtenção de preços e condições mais vantajosas para a Administração, conforme estabelece o art. 57, inciso II da Lei nº 8.666, de 1993.

$\S 1^{\circ}$ Os contratos de serviços de natureza continuada poderão ser prorrogados, a cada 12 (doze) meses, até o limite de 60 (sessenta) meses, quando comprovadamente vantajosos para a Administração, desde que haja autorização formal da autoridade competente e observados os seguintes requisitos:

I - os serviços tenham sido prestados regularmente;

II - a Administração mantenha interesse na realização do serviço;

III - o valor do contrato permaneça economicamente vantajoso para a Administração; e

IV- a contratada manifeste expressamente interesse na prorrogação.
} 
autorização da autoridade superior, o prazo de que trata o inciso II do caput deste artigo poderá ser prorrogado por até doze meses".

Ademais, o contrato de execução continuada possibilita a chamada prorrogação excepcional, para até 72 meses. Para que esta ocorra faz-se necessário observar os requisitos exigidos na prorrogação ordinária, alterando-se a exigência de prazo total de 60 meses para 72 meses e acrescendo-se a demonstração da excepcionalidade da situação.

Por outro lado, em situação que guarda similitude com a prorrogação excepcional, verifica-se que o Tribunal de Constas da União admite a possibilidade em abstrato de se dispensar a licitação por emergência, desde que reste comprovado que a ausência da contratação possa acarretar prejuízo a pessoas, obras ou serviços. É nesse sentido o teor do Acórdão nº 1876/2007 - Plenário TCU, assim ementado:

\footnotetext{
Para executar a prorrogação excepcional, no contrato de execução continuada, a Administração deve se justificar à luz da impossibilidade de o poder público seguir sem a prestação do serviço, ou seja, sua interrupção acarretará graves prejuízos ao desenvolvimento das atividades. Admitir a prorrogação não significa isentar os gestores públicos: será preciso apurar a responsabilidade pela situação.
}

Pelo art. 57, $\S 3^{\circ}$, tem-se que, em regra, o contrato administrativo não pode ser celebrado por prazo indeterminado. Essa é a grande regra dos contratos administrativos, especialmente porque a duração irrestrita dos mesmos ofenderia a regra da licitação.

O que se verifica, portanto, é que nos contratos de execução continuada existe previsão normativa expressa de como deve proceder a Administração Pública no tocante a renovação dos contratos. Aqui deve obediência ao texto normativo, conquanto o princípio da legalidade pauta diretamente os órgãos públicos, a rigor do artigo 37 da Constituição. Na prestação continuada, a lei regula de forma vinculada, ou seja, "está com isto declarando saber qual o comportamento que, a seu juízo, atenderá com exatidão, nos casos concretos, ao interesse público por ele almejado" (MELLO, 2008, p. $33)$.

Todavia, há se considerar que existem casos e casos, cada qual com suas peculiaridades, a exigir uma abordagem distinta no que se refere à vigência e à renovação.Éexatamenteo que deve pautar os contratos celebrados por escopo, tais como 
os narrados na introdução deste artigo (assessoria contábil e jurídica atrelada a êxito), eis que dependem do trâmite de umademanda contenciosa, que não tem prazo predefinido e não se mostra possível estipulá-laab initio. Portanto, incumbe analisar a problemática com base no sentido da Lei.

\begin{abstract}
Outra norma destinada a assegurar a integral aplicabilidade das restrições à assunção de obrigações que extravasem os limites dos créditos orçamentários se encontra no $\$ 3^{\circ}$ do art. 57. Ali se impõe a vedação de contratações com prazo indeterminado. Ou seja, é necessário que a contratação seja pactuada com um prazo específico e delimitado, o qual deve coincidir, em princípio, com a vigência do crédito orçamentário a que se vincular tal contratação.

Mas a regra deve ser interpretada em termos. Existem hipóteses em que é impossível estabelecer um prazo de vigência determinado e específico. Assim se passa em hipóteses nas quais a contratação envolve uma atividade que não comporta delimitação temporal. Não se trata da simples dificuldade de prever o período de tempo necessário à execução do objeto. Configura-se a impossibilidade dessa estimativa. Um exemplo marcante se relaciona com a prestação de serviços advocatícios. A contratação de um advogado para defesa dos interesses da Administração em processo judicial não comporta a delimitação de um prazo de vigência, eis que a contratação será acessória relativamente a um evento que se desenvolverá ao longo do tempo, sem cabimento de delimitação estimativa prévia.

Logo, a vedação a contratações por prazo indeterminado será aplicável quando for cabível e viável estabelecer um prazo limite para a execução das prestações a cargo do particular contratado.(JUSTEN FILHO, 2012, p. 830)
\end{abstract}

Não se quer deixar ao livre arbítrio do intérprete, mas exige-se um esforço hermenêutico para poder determinar a solução do caso. É preciso "fixar uma determinada relação jurídica, mediante percepção clara e exata da norma estabelecida pelo legislador" (FRANÇA, 1988, p. 21), sendo que quando omissa, propugna o estudo e a sistematização dos processos que devem ser utilizados para que a interpretação se realize.

Aqui, apesar de não haver disposição específica para o caso, a verificação da solução também perpassa pela legalidade, que possui um sentido amplo, isto é, a conformidade à lei e, sucessivamente, às subsequentes normas que, com base nela, a Administração expeça para regular mais estritamente sua própria discrição, adquirindo então um sentido mais extenso (MELLO, 2006).

E neste instante, exige-se uma atuação que vise "única e exclusivamente aquela que atenda com a absoluta perfeição a finalidade da lei" (MELLO, 2008, p. 33). O que não se permite é querer imputar aos contratos por escopo a solução legal estipulada para os contratos de prestação continuada. Por imposição da noção de igualdade, surge um 
nítido fator de desigualação (MELLO, 2010, p. 21), que indica uma solução melhor e de conformidade a integralidade das normas jurídicas.

\title{
II. OS CONTRATOS POR ESCOPO E A HIPÓTESE DO ART. 57 DA LEI DE LICITAÇÕES
}

A jurisprudência pátria, não obstante, vem pautando seu entendimento sobre a renovação dos contratos por escopo nos escólios dos contratos de prestação continuada, nos termos do difundido e aprofundado Parecer $\mathrm{n}^{\mathrm{o}}$. 13/2013/CPLC/DEPCONSU/PGF/AGU, no qual a AGU emitiu opinião no sentido de que mesmo o contrato de escopo submete-se a prazo e que não se admite sua prorrogação, após findo o prazo, devendo o contratante buscar participar de novo certame licitatório ou buscar indenização em caso de dano. São as conclusões de referido parecer:

\begin{abstract}
Para o objeto deste parecer, cabe destacar três peculiaridades formais do contrato administrativo: (a) necessidade, em regra, de prévia licitação, (b) a obrigatoriedade de formalização de contrato e dos seus termos aditivos, (c) a impossibilidade de celebração com prazo indeterminado. Assim, o procedimento legal para uma situação em que o prazo de vigência se avizinhe sem conclusão do objeto é a prorrogação do contrato com base em um dos motivos previstos no art. $57, \S 1^{\circ}$, da Lei 8.666/93.
\end{abstract}

Primeiramente, cabe assinalar que este Parecer carece de caráter vinculativo, posto não ter sido aprovado por decreto presidencial. É que conforme o art. 40 da Lei Complementar $\mathrm{n}^{\circ}$. 43, de 1993, apenas o parecer da Advocacia Geral da União aprovado e publicado juntamente com o despacho presidencial vincula a Administração Federal, cujos órgãos e entidades ficam obrigados a lhe dar fiel cumprimento. Mesmo assim, o referido Parecer vem orientando no seguinte sentido:

Assim, o procedimento legal para uma situação em que o prazo de vigência se avizinhe sem conclusão do objeto é a prorrogação do contrato com base em um dos motivos previstos no art. 57, $\S 1^{\circ}$, da Lei ${ }^{\circ}$ 8.666/93. Se o prazo de vigência é atingido sem prorrogação tempestiva, impõe-se reconhecer a extinção do contrato administrativo, assim entendido o instrumento formal e escrito celebrado mediante prévia licitação. Não resta dúvida de que remanesça uma situação fática que em termos jurídicos poderia ser assim definida: em razão da expiração do prazo de vigência, sobejam obrigações com suporte, no máximo, em contrato verbal. Como o contrato verbal é 
considerado nulo pela Lei $\mathrm{n}^{\circ}$ 8.666/93 (art. 60, parágrafo único, acima transcrito), não se pode admitir esteja respaldada na Lei essa situação de transmutação do contrato formal em verbal.

Pensando-se em priorizar ao máximo a segurança jurídica, referido parecer enaltece a necessidade de que suas contratações sejam amparadas por processo de inexigibilidade, a uma porque o seu serviço é singular e notório, e a duas porque, em preferindo a Administração Pública estabelecer um prazo (próprio) para o contrato, na hipótese do trânsito em julgado extrapolar tal prazo, poderá continuar patrocinando o processo, mas desde que realize novo procedimento de licitação.

O Tribunal de Contas do Estado do Paraná formaliza o entendimento de que a nova contratação, atendido o interesse público em harmonia com o contratado, deve ser realizado para a correta regularização:

É no sentido de que em contratos por escopo, nos quais se constata a suspensão por ordem da Administração, ainda que ultrapassado o prazo e não inexistindo a conclusão/ entrega do objeto, com o devido aceite da contratante, é possível invocar-se as implicações práticas de se iniciar um novo procedimento licitatório para permanecer com o antigo ajuste e se traçar um equilíbrio que satisfaça às partes. Em tese, a retomada de uma obra suspensa só será admissível se houver vantagem para o setor público contratante, atestando-se que refazer o procedimento licitatório - que é a regra, implicará em maiores retardos e prejuízos dos que aqueles já oriundos da paralisação. Assim o é, por que o bem maior a ser preservado é o interesse da coletividade. Mas há que se avaliar que não se pode, de outra sorte, impor prejuízo à contratada, cabendo às partes buscar o equilíbrio contratual (Acórdão nº 2674/14 - Tribunal Pleno).

Esse é o mesmo posicionamento que vem sendo exarado pelo Tribunal de Contas da União, que se dirige no sentido da necessidade de regularizar o caso mediante nova contratação:

Desse modo, muito embora no contrato de escopo tenha em vista a obtenção do objeto concluído, ou seja, o prazo depende da conclusão do objeto, o entendimento do TCU, seguido pela Advocacia-Geral da União, ainda é no sentido de vedar a celebração de aditivo ao contrato extinto, com vigência retroativa. Assim, expirado o prazo de vigência sem a conclusão do objeto, deve-se proceder à apuração do que não foi executado, realizando nova licitação para contratação da parte remanescente, bem assim deve a Administração Pública buscar ressarcimento em caso de eventual inadimplemento de obrigações contratuais por parte do particular (TC 006.216/2012-9 - Plenário. Data da Sessão: 26/8/2015). 
De acordo com os corolários jurisprudenciais acima, deve a Administração Pública formalizar novo procedimento licitatório caso não exaurido o objeto no prazo máximo previsto na lei, sempre em homenagem à ideia de que não se admitem contratos por prazos indeterminados na esfera pública. Estreita-se com disposições de segurança orçamentária e previsibilidade das despesas públicas.

Ocorre que, voltando-se novamente para a hipótese problema, como aplicar esse entendimento no caso de um escritório de advocacia que é contratado regularmente para conduzir uma demanda judicial ou uma assessoria contábil visando a recuperação de créditos cuja homologação depende da autoridade fazendária, cujos honorários estão atrelados ao êxito da medida?

O procedimento licitatório possui o propósito específico de selecionar, entre fornecedores qualificados, aquele que apresentar proposta mais vantajosa para a Administração. Regem a licitação os princípios de igualdade, da probidade administrativa, da vinculação ao edital, do julgamento objetivo, da legalidade, da impessoalidade, da moralidade e dos que lhe são correlatos (ANGÉLICO, 1985, p. 80).Duas são as finalidades da Licitação, sendo a primeira proporcionaràs pessoas a ela submetidas a obtenção da proposta mais vantajosa (a que melhor atende, especialmente em termos financeiros aos interesses da entidade licitante); e outra oferecer igual oportunidade aos que desejam contratar com a Administração Pública (GASPARINI, 2002).

Neste sentido, e seguindo o parecer da AGU ora comentado, deveria a Administração Pública realizar novo procedimento licitatório, permitindo que terceiros estranhos assumam as demandas em andamento? E como ficarão os honorários advocatícios atrelados ao êxito? A assessoria que deu início ao processo terá que repartir eventual êxito obtido?

Certamente que a solução proposta pelo Parecer $n^{\circ}$. 13/2013/CPLC/DEPCONSU/PGF/AGU não conserva a interpretação correta acerca da omissão legislativa existente sobre os contratos por escopo firmados com a Administração Pública. Exigir um novo procedimento licitatório não é a melhor solução, por ofensa aos predicados da efetividade, razoabilidade e proporcionalidade.

Proporcionalidade e razoabilidade realizam o papel de harmonização entre preceitos aparentemente conflitantes, "operando como limite a possibilidade de 
intervenção no âmbito de proteção dos direitos fundamentais", consistindo na proibição do excesso ou mesmo na proteção insuficiente dos direitos (SARLET, 2014, p. 228).A razoabilidade exige, sem oferecer a solução final, o "caminho do intérprete da lei não tão diversificadamente ou aleatório aos olhos do cidadão comum” (BASTOS, 2014, p. 166).

O esforço para encontrar a melhor solução a essa lacuna legislativa deve considerar a materialidade da situação, devendo ser discutida no âmbito de suas diversas funções, além da ótica do legislador (HABERLE, 2002, p. 52). E em nenhuma hipótese pode se compatibilizar com a injustiça (BASTOS, 2014, p. 171). A sociedade, enquanto condição do direito, estabelece a justiça como fim último, o que se realiza pela bilateralidade atributiva como forma ordenatória específica, tendo o Estado como unidade central do ordenamento jurídico (REALE, 2002, p. 703).

Neste sentido, não há qualquer compatibilidade com a razoabilidade exigir, no decurso do serviço, uma interrupção na execução do contrato administrativo para que terceiros tenham a possibilidade de participar da continuidade do processo.Na prática, exigir novo procedimento de contratação viola a garantia da efetividade do objeto.

De tal maneira que o princípio a pautar a solução para a presente discussão é a efetividade, que reflete tanto os anseios da maior vantajosidade da Administração Pública quanto as garantias fundamentais dos contratados. "O princípio da eficiência exige que a atividade administrativa seja exercida com presteza, perfeição e rendimento funcional" (MEIRELLES, 1999, p. 89).

O princípio da eficiência apresenta, na realidade, dois aspectos: pode ser considerado em relação ao modo de atuação do agente público, do qual se espera o melhor desempenho possível de suas atribuições, para lograr os melhores resultados; e em relação ao modo de organizar, estruturar, disciplinar a Administração Pública, também com o mesmo objetivo de alcançar os melhores resultados na prestação do serviço público (DI PIETRO, 2005, p. 84)

$\mathrm{O}$ princípio da legalidade, que pautou os termos do Parecer $\mathrm{n}^{\mathrm{o}}$. 13/2013/CPLC/DEPCONSU/PGF/AGU, cotejados pelas raízes da proporcionalidade e razoabilidade, deve ser harmonizado com as noções da efetividade.

A eficiência é considerada como ampliação dos serviços prestados à população, satisfação (percepção da qualidade) dos cidadãos em relação aos serviços e indicadores 
de desempenho (PIMENTA, 1998, p. 173). E a persecução do objeto contratado, até o seu final, é que melhor compatibiliza a situação dos contratos por escopo. De tal forma, a solução albergada pela jurisprudência é equivocada frente a uma análise ampla e sistêmica dos preceitos constitucionais que albergam os contratos administrativos.

\section{A CORRETA SOLUÇÃO ACERCA DO PRAZO DE VIGÊNCIA DOS CONTRATOS POR ESCOPO}

Afeito à noção da máxima efetividade, é certo concluir que os contratos com a Administração podem ultrapassar esses lapsos temporais, em situações excepcionais. Consoante literal disposição legal do art. 57 , $\$ 3^{\circ}$, da Lei $n^{\circ}$. 8.666/93, veda-se a celebração de contratos administrativos com prazo de vigência indeterminado. Ademais, conforme o caput do art. 57 da mesma Lei, a duração dos contratos administrativos deve ficar adstrita à vigência dos créditos orçamentários respectivos, ou seja, restrita ao exercício financeiro, que coincide com o ano civil. Para a situação de prestação de serviços de forma contínua, indica o II do mesmo artigo, que o prazo limite seria 60 meses.

Por primeiro, é preciso evidenciar que o limite de 60 meses é a regra, sendo admitidas exceções. Uma leitura rasa do art. 57 permite concluir que se admite a prorrogação em casos excepcionais, os quais devem necessariamente estar justificadas nos ato convocatório (zelosa elaboração do instrumento licitatório) ${ }^{6}$.

Tanto isso é verdade que a Lei das Parcerias permite que a contratação se estenda por até 35 (trinta e cinco) anos ${ }^{7}$.Outra regra explícita quanto à possibilidade de contrato com a Administração Pública ter mais que 60 meses é a que consta do art. 51

\footnotetext{
6 “A questão da duração dos contratos não se confunde com a prorrogação dos prazos neles previstos para execução das prestações. O prazo de vigência dos contratos é questão enfrentada no momento da elaboração do ato convocatório; a prorrogação do prazo para execução das prestações é tema relativo à execução do contrato. Portanto, lógica e cronologicamente as questões são inconfundíveis. Tecnicamente, os $\S \S 1^{\circ}$ e $2^{\circ}$ ficariam melhor se inseridos no capítulo destinado a regular a execução dos contratos administrativos. $\mathrm{O} \S 3^{\circ}$ deveria constar do art. 55" (JUSTEN FILHO, 2012, p. 827).

${ }^{7}$ Art. $5^{\circ}$ As cláusulas dos contratos de parceria público-privada atenderão ao disposto no art. 23 da Lei $\mathrm{n}^{\mathrm{o}}$ 8.987, de 13 de fevereiro de 1995 , no que couber, devendo também prever: I - o prazo de vigência do contrato, compatível com a amortização dos investimentos realizados, não inferior a 5 (cinco), nem superior a 35 (trinta e cinco) anos, incluindo eventual prorrogação.
} 
da Lei $n^{\text {o }}$. 8245/91, Lei das Locações ${ }^{8}$. E a Orientação Normativa AGU nº 06/2009 confirma essa assertiva:

A VIGÊNCIA DO CONTRATO DE LOCAC̃̃̃ DE IMÓVEIS, NO QUAL A ADMINISTRAÇÃO PÚBLICA É LOCATÁRIA, REGE-SE PELO ART. 51 DA LEI No 8.245, DE 1991, NÃO ESTANDO SUJEITA AO LIMITE MÁXIMO DE SESSENTA MESES, ESTIPULADO PELO INC. II DO ART. 57, DA LEI No 8.666, DE 1993.

INDEXAÇÃO: VIGÊNCIA. LIMITAÇÃO. CONTRATO DE LOCAÇÃO. IMÓVEL. ADMINISTRAÇÃO. LOCATÁRIA.

REFERÊNCIA: art. 62, $\S 3^{\circ}$ e art. 57 da Lei no 8.666 , de 1993; arts. 51 a 57 da Lei no 8.245, de 1991; Decisão TCU 828/2000 - Plenário.

O próprio art. $57, \S 4^{\circ}$, da Lei de Licitações, arrola algumas situações em que a licitação é dispensada (art. 24), em que o prazo ser superior a 60 meses. E um dos casos é "a compra ou locação de imóvel destinado ao atendimento das finalidades precípuas da administração, cujas necessidades de instalação e localização condicionem a sua escolha, desde que o preço seja compatível com o valor de mercado, segundo avaliação prévia".

\begin{abstract}
Existem casos em que a natureza do objeto do contrato exige prazos mais longos para execução, ultrapassando desde logo o limite da vigência do crédito orçamentário. A finalidade do dispositivo ora examinado é precisamente essa: assegurar que certas contratações diretas, diferenciadas por características especiais, sejam promovidas desde logo por um prazo de até 120 meses.

Considerada a questão sob outro enfoque, a existência de um objeto complexo e de execução demorada conduziria a que o particular se opusesse à realização de contratações sucessivas, cada qual com um período limitado de tempo. Isso criaria uma simples expectativa de direito à renovação - tal como apontado relativamente à regra do art. 57, inc. II. Portanto, haveria uma competência discricionária para a Administração renovar o contrato. A estipulação desde logo de um prazo mais longo assegura ao particular a garantia necessária à realização de investimentos com amortização de médio e longo prazo e ao comprometimento correspondente à complexidade do objeto contratado (JUSTEN FILHO, 2012, p. 838)
\end{abstract}

\footnotetext{
${ }^{8}$ Art. 51. Nas locações de imóveis destinados ao comércio, o locatário terá direito a renovação do contrato, por igual prazo, desde que, cumulativamente:

I - o contrato a renovar tenha sido celebrado por escrito e com prazo determinado;

II - o prazo mínimo do contrato a renovar ou a soma dos prazos ininterruptos dos contratos escritos seja de cinco anos;

III - o locatário esteja explorando seu comércio, no mesmo ramo, pelo prazo mínimo e ininterrupto de três anos.
} 
Tal sistemática é a forma razoável e proporcional de entendimento do direito. A regra veda a contratação por prazo superior a 60 meses, entretanto, existem situações no mundo real que segregam essa disposição, desde que sempre seja mantida a premissa da maior vantagem ao interesse público. Não se trata de mitigar a disposição legal, mas sim integrá-la frente às princípios estruturantes da própria regra em comento. $\mathrm{Na}$ doutrina a situação não passou despercebida:

\footnotetext{
Não se extinguem pelo decurso do prazo contratos cujo objeto for a execução de uma obra ou fornecimento de bens à Administração Pública contratante. Nesses casos o contrato restará automaticamente prorrogado se chegou ao seu termo formal sem a conclusão da obra ou sem a entrega dos bens. Essa é a inteligência, pois não se contratou uma obra inacabada, nem se promoveu a compra de uns poucos bens, ainda mais quando nada será pago pela conclusão da obra ou pelo fornecimento dos bens faltantes. (MEIRELLES, GASPARINI, 1990, p. 313)
}

Para tais autores, o contrato extingue-se apenas com a entrega da obra/produto, sendo que o prazo legal de 60 meses não incide sobre os contratos por escopo. Impõe à parte o dever de realizar uma conduta específica e definida, independentemente do tempo necessário a sua consecução, desde que por fatores alheios e absolutamente justificáveis.Nestes casos, o prazo de execução previsto no instrumento contratual é apenas moratório, não representando a extinção do pacto negocial, mas tão somente o prazo estipulado para sua execução (TORRES, 2013).

Há casos em que a referência à lei na Constituição, quer para satisfazer tão-só as exigências do princípio da legalidade, quer para atender hipóteses de reserva (infra), não exclui a possibilidade de que a matéria seja regulada por um ato equiparado, e ato equiparado à lei formal (SILVA, 2009), recebendo um sentido amplo, sistemático e de acordo com a finalidade da contratação.

Nestes contratos o prazo é apenas limitativo do cronograma físico, e será prorrogado (com ou sem mora das partes) tantas vezes quantas sejam necessárias para a conclusão da obra independentemente de previsão contratual. Na realidade, a hipótese envolvendo os contratos por escopoconstitui uma exceção à própria regra instalada no caput do art. 57 da Lei de Licitações, como acima demonstrado, de terem os contratos prazo de vigência determinado. 
Estabelece esse dispositivo que "a duração dos contratos regidos por esta Lei ficará adstrita à vigência dos respectivos créditos orçamentários, exceto quanto aos relativos: I - aos projetos cujos produtos estejam contemplados nas metas estabelecidas no Plano Plurianual, os quais poderão ser prorrogados se houver interesse da Administração e desde que isso tenha sido previsto no ato convocatório".

Verifica-se, com apoio na doutrina, que este dispositivo reforça a ideia de que o contrato envolvendo prestação de serviços advocatícios não se submete ao disposto no art. 57, II, da Lei de Licitações, para efeito de ser limitado no tempo ao período máximo de 60 meses.

A primeira exceção envolve projetos de longo prazo, desde que previstos no plano plurianual, tal como previsto no próprio art. $167, \S 1^{\circ}$, da $\mathrm{CF} / 88$, acima transcrito.

A previsão no orçamento plurianual é condição inafastável para a contratação em período superior ao prazo de vigência do crédito. Desse modo, evita-se uma superposição da atividade contratual da Administração às demais funções do Estado. A inserção no plano plurianual faz presumir que a contratação retrata uma avaliação meditada e planejada do Estado.

Observe-se que projetos de longo prazo envolvem, usualmente, contratos de execução instantânea, mas com objeto extremamente complexo. A duração no tempo não deriva da repetição de condutas homogêneas, mas da dificuldade de completar uma prestação que exige atividades heterogêneas. A hipótese de prorrogação de prazo relaciona-se com a impossibilidade concreta e material de completar a prestação no prazo previsto.

Na hipótese do inc. I, é possível tanto pactuar o contrato por prazo mais delongado como produzir sua prorrogação. Ambas as alternativas são comportadas pelo dispositivo. Assim, o contrato para construção de uma hidrelétrica pode ser pactuado com prazo de execução de cinco anos. Não é necessário pactuar o prazo de um ano, "prorrogável" sucessivamente. Essa alternativa, aliás, afigura-se inadequada. A Administração deve determinar, em termos precisos, o prazo necessário à execução do projeto. Fixado o prazo, o particular terá o dever de cumprir o cronograma e a Administração o de realizar os pagamentos apropriados. A faculdade de prorrogação não se destina a ser utilizada permanentemente(JUSTEN FILHO, 2012, p. 838).

O ideal no caso dos contratos celebrados por escopo é que não haja prazo, mas, pelos comentários acima, dessume-se que se a Administração Pública considerar prudente prever um prazo, como, por exemplo, de 60 meses, uma vez passado esse prazo, procede-se à prorrogação, não havendo aqui o limite de 60 meses e nem a obrigação de o contrato ser estabelecido por períodos de 12 meses e prorrogado, via aditivo, por outros períodos de 12 meses. 
Fundamentada a contratação no art. 57, II, da Lei de Licitações, deve estar expresso na justificativa que o contrato é para promover demanda judicial e que a duração do contrato está atrelada à duração do mesmo, o que pode ser estimado, analisando-se a média de duração das demandas judiciais, mas não precisado. Transitado em julgado o pedido, termina-se o contrato. Neste sentido ingressa a jurisprudência do Tribunal de Contas de alguns Estados brasileiros, iniciando-se pelo Distrito Federal ${ }^{9}$ :

Com relação ao prazo de duração do ajuste, perfilho o entendimento de que este tipo de relação contratual não pode ter sua vigência anteriormente fixada ou estar adstrita a determinado período, conforme artigo 57 da Lei de Licitações e Contratos. A vigência dos contratos de prestação de serviços advocatícios está relacionada com a duração da ação judicial que o motivou. Interrompê-lo antes do trânsito em julgado da lide é atentar contra a confiança do contratante, a eficácia e a economicidade do ajuste.

Em medida semelhante optou o Tribunal de Contas do Estado de São Paulo ${ }^{10}$ :

Como demonstrado pela instrução processual, os aditivos em exame estão em boa ordem formal, preenchendo os requisitos legais. Aqui cuida-se de contrato por escopo, que somente se extingue pela conclusão do seu objeto,e que o atraso havido, se deu por motivos alheios à vontade da contratada. Nesse sentido e no esteio dos órgãos instrutivos, julgo regulares os termos em exame bem como legais os atos determinativos das despesas decorrentes.

E finalmente o Estado do Paraná, agora na jurisprudência do Tribunal de Justiça do Estado ${ }^{11}$ :

Em se tratando de contrato por escopo, considere-se prorrogado o prazo da execução do contrato até o presente momento, tendo em vista as alterações solicitadas pelo Tribunal de Justiça. Diante das razões de interesse público acima elencadas, justificável o atraso na execução do pactuado até presente momento, bem como é de possível deferimento o pedido de prorrogação de 60 (sessenta) dias solicitado pela empresa, para a execução dos serviços extras, que se iniciará no dia subsequente a assinatura do respectivo termo aditivo.

\footnotetext{
${ }^{9}$ BRASIL. Tribunal de Contas do Distrito Federal. Processo no 342/1998. Conselheira do TCDF: Ministra Marli Vinhadeli. Sessão de 07 out. 1999. Disponível em: http://www.tc.df.gov.br/dga/sedoc/Votos.pdf.

${ }^{10}$ TCE-SP -Conselheiro Dr. Robson Marinho em 14 de Abril de 2011.

${ }^{11}$ PROTOCOLO No 39.862/2013. Decisão Publicada no Diário Eletrônico do Tribunal de Justiça do Paraná em 27 de Abril de 2015 - Edição nº 1553
} 
Há de se tomar cuidado, também nesse caso, haja vista que para a prorrogação se configurar faz-se necessário: a) que o projeto esteja contemplado pelo Plano Plurianual; b) que a prorrogação venha expressamente prevista no instrumento do contrato e c) que a Administração tenha interesse em estender a vigência.

Por sinal, a Constituição estabelece, em seu art. 167, $1^{\circ}$, que nenhum investimento cuja execução ultrapasse um exercício financeiro poderá ser iniciado sem prévia inclusão no Plano Plurianual ou sem lei que autorize sua inclusão, sob pena de crime de responsabilidade.

Logo, deve-se ter como regra que todos os contratos por ela celebrados junto com o Poder Público devem estar previstos no Plano Plurianual, sob pena de sofrer prejuízos nos pagamentos, por falta de previsão orçamentária.Constituem exceção à regra do caput do art. 57, de forma que, não se podendo precisar o prazo no qual o objeto irá se concretizar, nada obsta que o contrato a) fique sem prazo determinado ou que na cláusula atinente ao prazo esteja expresso que o contrato vigorará pelo prazo em que viger o processo judicial/administrativo; b) ou pode a Administração Pública estabelecer um prazo mais dilargado e prever a prorrogação por iguais e sucessivos períodos.

No primeiro caso, inexiste razão para a formalização de aditivos contratuais. Logo, os contratos que se encontram em vigor e que já ultrapassaram o prazo de 12 meses não necessitam ser aditados, até porque isso configuraria uma irregularidade, já que se reclama o aditivo logo após o esgotamento do prazo, caso fosse esse o caso.

Até mesmo é possível que os contratos ultrapassem o período de um exercício financeiro. Segundo a IN-SLTI nº. 02/2008, no seu art. 30, p. $4^{\circ}$, há previsão implícita quanto à possibilidade de que o contrato seja estabelecido por prazo superior a um exercício financeiro, o que também evidencia que os aditivos contratuais, para prorrogação, nem sempre são necessários:

Art. 30. A duração dos contratos ficará adstrita à vigência dos respectivos créditos orçamentários, podendo, quando for o caso, ser prorrogada até o limite previsto no ato convocatório, observado o disposto no art. 57 da Lei $8.666 / 93$.

$\S 4^{\circ}$ Nos contratos cuja duração, ou previsão de duração, ultrapasse um exercício financeiro, indicar-se-á o crédito e respectivo empenho para atender à despesa no exercício em curso, bem como de cada parcela da despesa relativa à parte a ser executada em exercício futuro, com a 
declaração de que, em termos aditivos ou apostilamentos, indicar-se-ão os créditos e empenhos para sua cobertura.

Em optando a Administração Pública por enquadrar os contratos à hipótese do art. 57, I, da Lei de Licitações e estabelecer um prazo, a prorrogação pode restar necessária caso o processo judicial não tenha fim no período previsto.

Cautela há que se tomada, todavia, também em relação à prévia e cuidadosa análise do ato convocatório, no sentido de que nele esteja prevista a possibilidade da prorrogação, pois "não é possível que se instaure a licitação sem explícita previsão acerca do tema. Os eventuais interessados deverão ter plena ciência da possibilidade de prorrogação" (JUSTEN FILHO, 2012, p. 836).

A prorrogação do contrato, quando necessário, enfim, exige, além da acima mencionada previsão de prorrogação no Edital e no Contrato, manifestação da autoridade fiscalizadora do contrato; não haver solução de continuidade nas prorrogações; se houver oferecimento de garantia, a necessidade de sua renovação; objeto e escopo do contrato inalterados pela prorrogação; interesse da Administração e do contratado declarados expressamente; manutenção das condições de habilitação pelo contratado; inalterabilidade das condições de remuneração.

Compete à Administração avaliar a conveniência de se "prorrogar" o acordo, porque medida decorrente do poder discricionário. A ordem jurídica, quando permite a prorrogação, não estabelece sua obrigatoriedade, cabendo ao gestor público analisar a conveniência/oportunidade de utilização do permissivo legal, com vistas a alcançar o interesse público.

Por este aspecto é que se deve primar, cada vez mais, por se defender que os contratos em questão não devem ter prazo definido, pois isso evita a necessidade da prorrogação, submetida ao juízo de mérito, discricionário, nas mais das vezes, da Administração Pública contratante.

Deve-se buscar que os contratos prevejam um prazo definido, próximo àquele necessário para a finalização da demanda judicial/administrativa, com seu trânsito em julgado, especialmente nas hipóteses de contratações que resultaram de inexigibilidade de licitação, onde é manifestamente impensável a realização de novo procedimento de contratação. 
Nesse momento, associado à diferença entre "prorrogação" e "renovação" cabe registrar que, conforme se depreende do $\S 2^{\circ}$ do art. 57 , toda prorrogação de prazo deve ser justificada. A apresentação de justificativa, acompanhada dos pressupostos de fato e de direito, é eficaz aliada do agente público, além de cumprir o princípio da motivação, inserido no art. $2^{\circ}$ da Lei $\mathrm{n}^{\circ} 9.784 / 99$, e de permitir o controle do ato pelos interessados ou por qualquer cidadão.

Por fim, os termos de aditamento devem ser celebrados previamente à expiração do prazo previsto na avença, de modo a evitar a execução de serviços sem cobertura contratual (Acórdão nº 740/2004 - Plenário do TCU).

Os contratos por escopo que estejam atrelados ao êxitoem demanda judicial, a rigor, sempre ultrapassarão o prazo de 12 meses, prazo de vigência, por excelência, dos créditos orçamentários. Neste caso, para além da previsão na Lei Orçamentária anual das despesas que podem decorrer do contrato, faz-se imprescindível que haja previsão no Plano Plurianual (PPA).

Dentro do contexto do orçamento, o objetivo do PPA é instrumento de planejamento estratégico de grande prazo.Toda ação do governo obrigatoriamente deve ser executada por meio de programas, que são instrumentos de organização da ação governamental visando à concretização dos objetivos pretendidos, sendo mensurado por indicadores estabelecidos no plano plurianual.

Nesse sentido, o PPA representa o "querer fazer" do Governo. A Lei de Diretrizes Orçamentárias - LDO, por sua vez, representa o "poder fazer" e a Lei Orçamentária - LO - o “fazer”.Logo, os contratos celebrados pela Consulente e a celebrar devem contar com previsão de créditos orçamentários não apenas na LO e na LDO, mas também no PPA.

A propósito, o art. 165 , p. $1^{\circ}$, da $\mathrm{CF} / 88$, estabelece que "a lei que instituir o plano plurianual estabelecerá, de forma regionalizada, as diretrizes, objetivos e metas da administração pública federal para as despesas de capital e outras delas decorrentes e para as relativas aos programas de duração continuada". Os contratos em questão podem ser enquadrados na regra do art. 57, I, da Lei de Licitações, sendo concebido com necessário para concretização de um programa de duração continuada, e como tal ter as despesas afins inseridas no PPA. 
Ademais, é de se assinalar que não se reputa irregular o contrato que tem prazo de vigência submetido ao trânsito em julgado do processo judicial/administrativo, já que a obrigação inerente ao contrato de execução instantânea é exatamente o patrocínio do processo até resposta final da autoridade julgadora. Logo, apor no contrato que a vigência submeter-se-á ao trânsito em julgado do processo significa atribuir-lhe um prazo. Um prazo impróprio, mas não indeterminado, que é o que se veda pela Lei de Licitações e Contratos Administrativos.

\section{CONSIDERAÇÕES FINAIS}

A Lei 8.666/1993 traz um arcabouço normativo pautado pela segurança jurídica, visando compatibilidade a noção de legalidade com a segurança jurídica necessária para os atos da Administração Pública. Como característica fundamental, estabelece a isonomia na contratação com o Poder Público, sempre na defesa da vantajosidade do Estado.Neste sentido que se desenvolveu, a rigor do artigo 57, todo um arcabouço legislativo acerca dos contratos de prestação contínua.

Sobre tal dispositivo, a Advocacia Geral da União desenvolveu consistente parecer (Parecer $n^{\circ}$. 13/2013/CPLC/DEPCONSU/PGF/AGU) que acabou por orientar a Administração Pública, especialmente os Tribunais de Contas, em como prosseguir quando verificado o decurso de prazo máximo previsto na legislação, qual seja, o prazo máximo de 60 anos.

$\mathrm{Na}$ interpretação jurisprudencial, exige-se respeito ao contrato escrito, com prazo determinado e limitado aos 60 meses. Caso a execução do serviço extrapole esse valor período, é necessário formalizar novo procedimento licitatório, ainda que por emergência, até resolução final da nova contratação.O problema está em aplicar esse mesmo entendimento para os contratos por escopo, em especial naqueles em que o pagamento está atrelado ao êxito da medida. Nestes casos, a melhor solução não pode ser aquela sugerida pela Advocacia Geral da União.

Há uma lacuna legislativa para o caso, não cabendo a aplicação analógica acerca dos contratos de serviços continuados. São situações diversas que não admitem a mesma solução. No caso do escritório de advocacia que é contratado regularmente para conduzir uma demanda judicial ou uma assessoria contábil visando à recuperação de 
créditos cuja homologação depende da autoridade fazendária, cujos honorários estão atrelados ao êxito da medida, admite-se extrapolar o prazo de 60 meses indicado no artigo 57 da Lei 8.666/1993, e tampouco mostra-se necessário realizar sucessivas prorrogações.

Essa resposta advém dos corolários da razoabilidade, proporcionalidade e efetividade, que pautam pela possibilidade do licitante vencedor prestar o serviço até o seu escopo estiver exaurido.Pensar diferente é desconsiderar o princípio da efetividade, além de macular as garantias do prestador dos serviços.

Este tipo de situação deve ser tratada de forma excepcional, devendo estar devidamente justificado na consecução do Edital e no Contrato, em perfeita harmonia com a manifestação da autoridade fiscalizadora, descrevendo-se o objeto e o escopo inalterados até o exaurimento do objetivo contratado. Essa é a melhor interpretação e aplicação do direito, seja para a Administração Pública, seja para aquele que pretende executar serviços para o Poder Público.

\section{REFERÊNCIAS}

ANGÉLICO, João. Contabilidade Pública, São Paulo, Editora Atlas; 1985;

BASTOS, Celso Ribeiro. Hermenêutica e Interpretação Constitucional. 4 ed. São Paulo: Malheiros, 2014;

BRASIL. Constituição da República Federativa do Brasil de 1988. Legislação Federal. Senado Federal. Disponível em: http://www.planalto.gov.br/ccivil_03/constituicao/constituicao.htm. Acesso em: 12 ago. 2016;

. Lei no 8.666, de 21 de junho de 1993. Legislação Federal. Senado Federal. Disponível em: http://www.planalto.gov.br/ccivil_03/leis/L8666cons.htm. Acesso em: 12 ago. 2016; 
Instrução Normativa $n^{\circ}$ 02, de 30 de abril de 2008. Secretariade Logística e Tecnologia da Informação do Ministério do Planejamento, Desenvolvimento e Gestão. Disponível em: http://www.comprasgovernamentais.gov.br/paginas/instrucoesnormativas/instrucao-normativa-no-02-de-30-de-abril-de-2008-1. Acesso em: 12 ago. 2016;

. Orientação Normativa $\mathrm{n}^{\circ}$ 38, de 13 de dezembro de 2011. Advocacia Geral da União. Disponível em: http://www.agu.gov.br/atos/detalhe/418805. Acesso em: 12 ago. 2016;

Parecer $n^{\circ}$ 01/2016/CPLC/DEPCONSU/PGF/AGU. Advocacia Geral da União. Disponível em: www.agu.gov.br/page/download/index/id/19003176. Acesso em: 12 ago. 2016;

. Tribunal de Contas do Distrito Federal. Processo no 342/1998. Conselheira do TCDF: Ministra Marli Vinhadeli. Sessão de 07 out. 1999. Disponível em: http://www.tc.df.gov.br/dga/sedoc/Votos.pdf.Acesso em: 12 ago. 2016;

- Tribunal de Contas da União. ACÓRDÃO 1876/2007 ATA 38 PLENÁRIO - 12/09/2007. Relator: AROLDO CEDRAZ. Disponível em https://contas.tcu.gov.br/juris/Web/Juris/ConsultarTextual2/Jurisprudencia.faces?grupo Pesquisa=JURISPRUDENCIA\&textoPesquisa=PROC:840319996. Acesso em: 17 ago. 2016;

. Tribunal de Contas do Paraná. Sessão 24/04/14 - Processo no 211831/14 -

Acórdão $\quad \mathrm{n}^{\circ} \quad 2674 / 14 \quad-\quad$ Tribunal Pleno. Disponível em: http://www1.tce.pr.gov.br/conteudo/sessao-240414-processo-n\%C2\%BA-21183114acordao-n\%C2\%BA-267414-tribunal-pleno/254849/area/242. Acesso em: 17 ago. 2016;

DI PIETRO, Maria Sylvia. Direito Administrativo. São Paulo, Editora Atlas, 2005;

FRANÇA, Limongi. Hermenêutica Jurídica. $2^{\text {a }}$ Ed. São Paulo: Saraiva, 1988;

GASPARINI, Diogenes. Direito Administrativo. São Paulo: Saraiva, 2002;

HABERLE, Peter. Hermenêutica constitucional. Trad. Gilmar Mendes. Porto Alegre: Sergio Antonio Fabris, 2002;

JUSTEN FILHO, Marçal. Comentários à Lei de Licitações e Contratos Administrativos. $15^{\mathrm{a}}$. edição. São Paulo: Dialética, 2012;

MARTINS, Fernando Rodrigues. Direito em diálogo das Fontes. Belo Horizonte: De Plácido, 2013;

MEIRELLES, Hely Lopes. Licitação e Contrato Administrativo. $15^{a}$ ed.. São Paulo: Malheiros, 1990;

. Direito Administrativo. São Paulo, Editora Malheiros, 1999; 
MELlo, Celso Antônio Bandeira de. Curso de Direito administrativo. $20^{\mathrm{a}}$ ed. São Paulo: Malheiros, 2006;

. Discricionariedade e controle jurisdicional. 2. Ed. São Paulo: Malheiros, 2008

Malheiros, 2010;

O conteúdo jurídico do princípio da igualdade. 3 ed. São Paulo:

PIMENTA, Carlos. A reforma gerencial do Estado brasileiro no contexto das grandes tendências mundiais. Revista de Administração Pública, 32 (5), 173-199, set./out. 1998;

SARLET Ingo Wolfgang, MARINONI, Luiz Guilherme, MITIDIERO, Daniel. Curso de Direito Constitucional. 3 ed. São Paulo: RT, 2014;

SILVA, José Afonso da. Curso de Direito Constitucional Positivo. 32 edição. São Paulo: Editora Malheiros, 2009;

LICITAÇÕESe contratos: orientações e jurisprudência do TCU. Tribunal de Contas da União. 4. ed. rev., atual. eampl. Brasília: TCU, Secretaria-Geral da Presidência; Senado Federal, Secretaria Especial de Editoração e Publicações, 2010;

TORRES, Ronny Charles Lopes de. Leis de licitações públicas comentadas. $5^{\mathrm{a}}$ edição. Salvador: JusPODIVM, 2013. 